\title{
Global-scale comparisons of human land use: developing shared terminology for land-use practices for global change
}

\author{
Kathleen D. Morrison', E. Hammer², L. Popova ${ }^{3}$, M. Madella4, N. Whitehouse ${ }^{5}$, M-J Gaillard ${ }^{6}$ and LandCover6k \\ Land-Use Group Members*
}

\begin{abstract}
Although archaeological data are needed to understand the impacts of past human land use on the Earth system, synthesis is hampered by a lack of consistent categories. We develop hierarchical and scalable land-use classifications for use across the globe.
\end{abstract}

Human land-use practices have been highly variable over the course of the Holocene, a diversity evident in the differentiated effects of human activity on land cover. Historically, agriculture was one of the most significant forms of land use, but even mobile huntergatherers transformed land cover through landscape-scale burning (Bliege Bird 2008). Livestock-keeping, plowing, irrigation, and the production of metal, ceramics, and bricks, have also been drivers of historical change. It is important to understand the aggregate effects of anthropic activities on the Earth system, but significant challenges are posed by: (1) the complexity, diversity and mosaic nature of human land use itself (Fig. 1); (2) the need to develop a uniform vocabulary and terminology for land-use practices around the globe and across the span of human history; (3) the sheer quantity of evidence to be analyzed; and (4) the lack of a tradition of global-scale comparisons. Nevertheless, there is a deep reservoir of expertise about land-use and land-cover transitions waiting to be tapped. One goal of LandCover6k is to improve understanding of the relationships between land-use and land-cover changes (Gaillard et al., this issue). By comparing land-use and landcover trends, we can better disentangle anthropogenic forms of land- cover change from climatic or other drivers.

\section{The Land Cover6k land-use classification} Comparison of land-use practices is complicated by regionally- and historically-specific terminologies. Even where the same category is used, there may be disagreement about the applicability of the term. "Agriculture", for example, is subject to multiple interpretations about boundary conditions. In part, classificatory chaos reflects the complexity of land use itself. People typically practice multiple forms of land use simultaneously, and shift strategies as needed. This is not merely a complication but a critical area of research relating to resilience, sustainability and fundamental processes of change. We have sought to retain as much of this important complexity as possible while also making the simplifications necessary for global comparison.

To develop systemic, global-scale comparisons of land-use/land-cover relationships, it is first necessary to employ a consistent set of categories. Accordingly, and in consultation with scholars from across the globe, we developed a unified set of land-use categories (Fig. 2). The classification is hierarchical and expandable, with the highest level of generality designed to facilitate global analyses (level 1), and lower-order categories for regional studies (levels 2-3). Like all classifications, it simplifies complex systems, but such tradeoffs are offset by the analytical possibilities for large-scale analyses and minimized by the multi-level structure of the classification.

It is important to note that categories refer to activities known to have taken place in a particular location and time and do not necessarily reflect specific groups of people. Thus, if we know that both farming and pastoralism took place in the same area, we can include both categories in the database regardless of whether or not pastoralists were socially distinct from farmers. Categories refer to land (e.g. animal herding is taking place in this location) rather than to people (people here are herders), with the database designed to allow multiple forms of land use to co-exist.

\section{Land-use types}

The most general classification of land-use types was developed during a PAGESsponsored workshop (Morrison et al. 2016) and refined during several regional workshops and an INQUA-sponsored thematic workshop (HoLa). The term "No evidence of land use" is to be used in cases where archaeologists are reasonably certain that humans were not present. "Minimal or extensive land use" applies to areas which are, for example, crossed by a few roads, but are not otherwise in use. Hunting and gathering encompasses both mobile and sedentary foragers; we presume that tending of wild plants is often a feature of forager land use. Within archaeology, much scholarly effort has been expended on the precise contours of early farming and its differentiation from other forms of land use; we recognize this complexity and have built in levels of detail sufficient for regional-scale studies.

Agriculture is the most internally diverse land-use class, reflecting both its history and significance to landscape transformation. The level 2 classification of agricultural forms (Fig. 2) is therefore the most finely subdivided. Not all croplands are

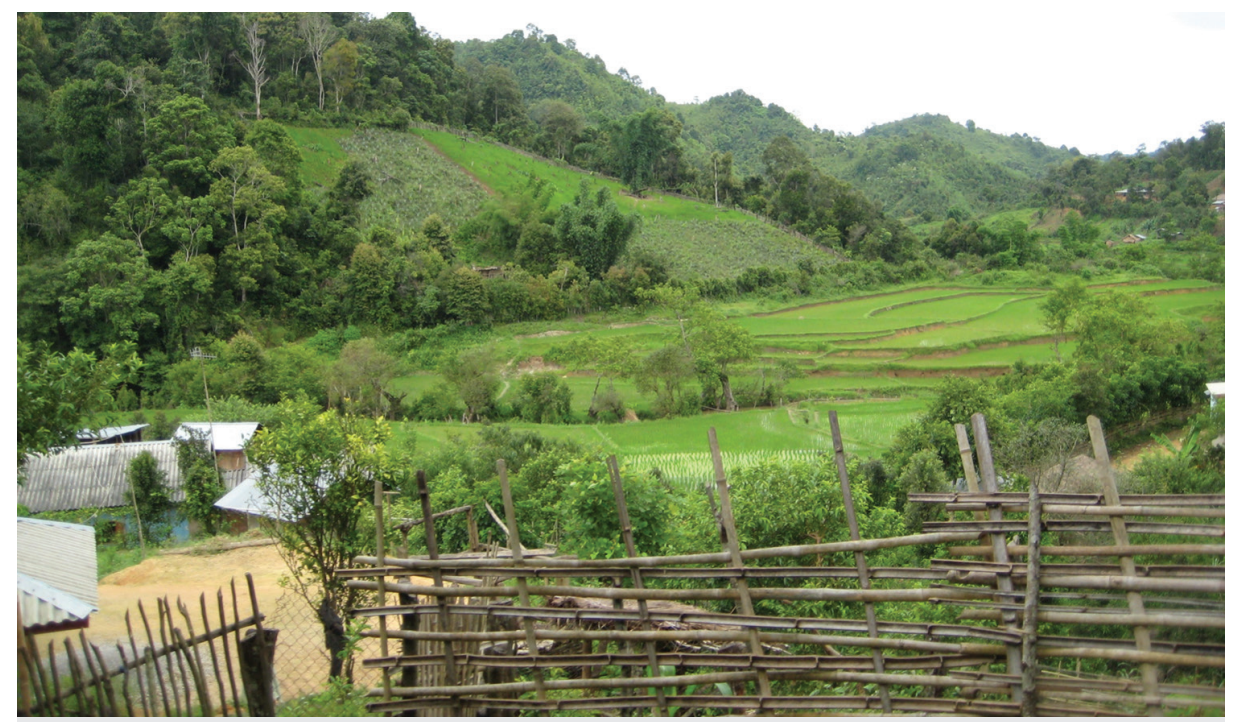

Figure 1: Land-use systems are often mosaics, incorporating multiple forms of land use simultaneously. In this village in the Philippines, irrigated rice fields are grown near the settlement, while the hillsides are used for swidden farming. This land-use regime would be classified as agriculture in level 1 of the LandCover6k land-use classification (Fig. 2), flooded-field farming and swidden in level 2, and rice paddy/taro pondfield in level 3. Domesticated animals and crops would be coded separately. Image credit: O. Paredes. 
equivalent. In the tropics, for example, forms of arboriculture typically mimic the structure of the natural forest in terms of taxonomic diversity and vegetation structure; arboriculture plots may be relatively short-lived, making differentiation between "natural" and anthropogenic vegetation difficult over the long term. In some temperate regions, domesticated grazers, such as cattle, are associated with human-made pastures, a practice uncommon in Africa and Asia. The manipulation of water and of slope are often critical components of agricultural practice; irrigated, ditched and terraced landscapes are found across the globe, associated with a range of cropping practices. Understandings of the aggregate effects of human land use on the Earth system must address this diversity, but also develop modes of comparison that make it possible to aggregate the vast, scattered body of archaeological and historical data.

Pastoralism without farming is sufficiently important in some regions that it was made a global (level 1) category. Where farming accompanies herding, however, our classification places this under the heading of agriculture. Similarly, the category "urban and extractive industries", which includes land used for cities, mines, and quarries, was included at the global level because of its significant impact on land cover, despite its often-limited spatial extent. More detailed discussions and definitions of the land-use classifications are in preparation.

\section{Land-use variables in the database}

Our system allows the comparison of archaeological and historical data from across the globe and throughout the Holocene. It does not, however, provide systemic data on specific land-use practices of interest to climate modelers that may cross-cut categories. For example, mobile hunter-gatherers in Australia and North America who used fire as part of their subsistence strategies changed regional vegetation in ways that mobile hunter-gatherers not practicing landscape burning did not. In this case, a single land-use category masks a significant difference. Similarly, tillage, livestock production, irrigation, and pyrotechnologies may have important land-cover effects that complicate simple categorization. For example, metal production, which uses large quantities of wood (Jouffroy-Bapicot et al. 2007), can occur in diverse farming or urban contexts and is not necessarily linked to a specific land-use regime. Similarly, the same overall land-use regime (e.g. dry farming) may be carried out with either digging sticks or plows, but the choice of technology itself has implications for carbon cycling. Tillage, like burning and irrigation, may impact carbon cycling independently of the crop grown. Accordingly, our classification includes some variables within land-use groups (irrigation and large-animal husbandry are part of level 2 classifications), while others are coded separately.

\section{Building a global land-use database}

Although archaeologists and historians

have amassed a huge amount of information

Level 1

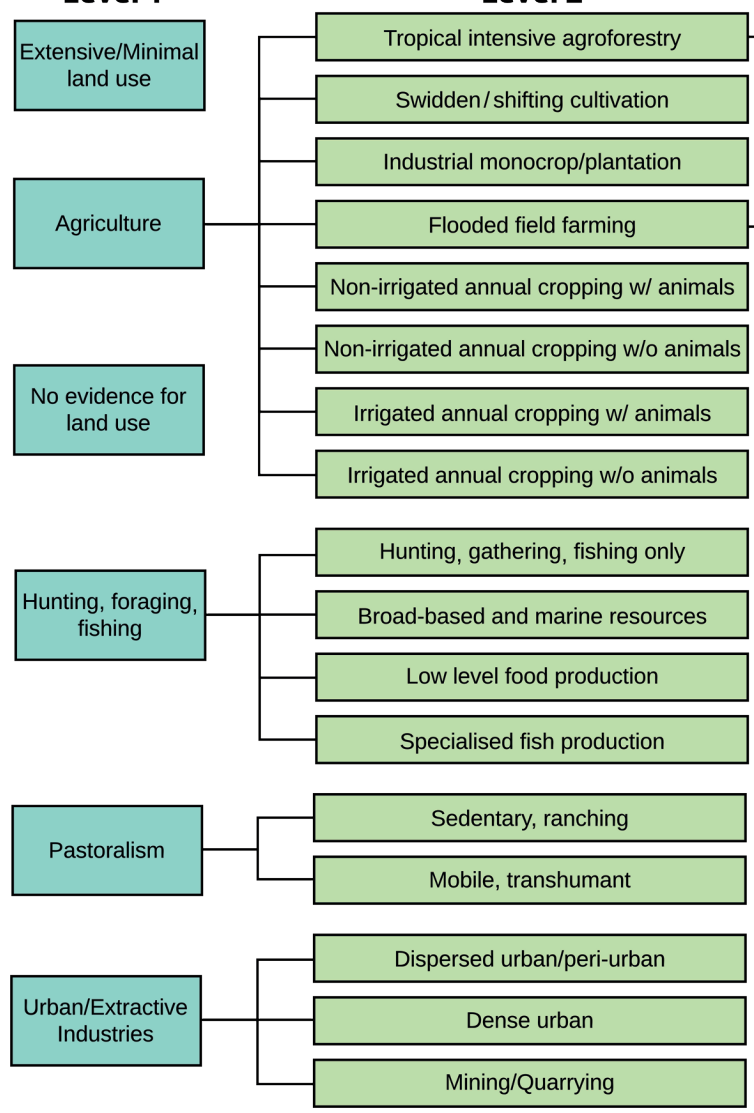

Figure 2: The LandCover6k land-use classification matrix

about past human land use, these data cannot be directly compared or quantified without recourse to a single vocabulary. Working in consultation with climate modelers and keeping in mind the need to better understand the links between land use and land cover, we have developed a simple but capacious classification system for forms of land use and specific land-use activities that can be applied at a global level across the Holocene. We hope this framework - the product of several years of widespread consultation - will allow the important archives of archaeological and historical data to be marshaled to address critical issues of global change.

\section{ACKNOWLEDGEMENTS}

HoLA, the Holocene Global Land Use International Focus Group was supported by INQUA IFG 1702F. Thanks also to the Universities of Chicago and Pennsylvania for support.

\section{AFFILIATIONS}

'Department of Anthropology and Museum of Archaeology and Anthropology, University of Pennsylvania, Philadelphia, USA

${ }^{2}$ Department of Near East Languages and Civilization, University of Pennsylvania, Philadelphia, USA

${ }^{3}$ Barrett Honors College, Arizona State University, Tempe, USA

${ }^{4}$ Department of Humanities (CaSEs, ICREA), University Pompeu Fabra, Barcelona, Spain

${ }^{5}$ School of Geography, Earth and Environmental Sciences, Plymouth University, UK

${ }^{6}$ Department of Biology and Environmental Science, Linnaeus University, Kalmar, Sweden

*J Aleru, U Ibadan, NG; M Arroyo-Kalin, U College London, UK; A Bauer, Stanford U, US; C Betancourt, U Bonn, DE; S Biagetti, U Pompeu Fabra, ES; R Bishop, U College, IE; O Boles, U Pennsylvania, US; CR Clement, INPA, BR; P Cruz, CONICET, AR; BS Dennis, Nat C Youth
Level 3 Agroforestry $1 \mathrm{w}$. soil enrichment

Agroforestry 2 w/o soil enrichment

Agroforestry 3

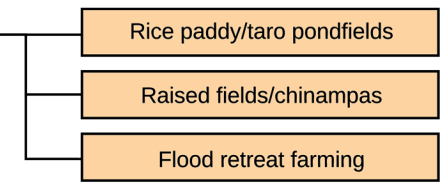

Develop, NG; A Ekblom, Uppsala U, SE; K Elizabeth, Kyambogo U, UG; E Ellis, U Maryland, US; S Flantua, U Bergen, NO; T Foster, U Tulsa, US; D Gronenborn, Johannes-Gutenberg-U, DE; M Hannaford, Utrecht U, NL; J Iriarte, U Exeter, UK; A Junqueira, U Wageningen, $\mathrm{NL}$; A Kay, U Lausanne, CH; K Klein-Goldewijk, Utrecht U, NL; J Kolář, Masarykovy U, CZ; C Lancelotti, U Pompeu Fabra, ES; P Lane, Uppsala U, SE; C Leclerc, CIRAD, FR; M-P Ledru, IRD, FR; C Lemmen, Helmholtz-Zentrum Geesthacht, DE; C Levis, INPA, BR; U Lombardo, U Pompeu Fabra, ES; S Maezumi, U Exeter, UK; M Manyanga, U Zimbabwe, ZW; R Marchant U York, UK; N Maughan, Aix-Marseilles U, FR; F Mayle, U Reading, UK; C McMichael, U Amsterdam, NL; S Monprapussorn, Srinakharinwirot U, TH; CP Moraes, U Fed Oeste do Pará, BR; R Muchena, Chesa Forest Research Station, ZW; EG Neves, U São Paulo, BR; S Pandey, Birbal Sahni Inst Palaeobot, IN; L Phelps, U Lausanne, CH; Z Pinke, Szent István U, HU; P Riris, U College London, UK; S Rostain, CNRS, FR; T Russel, U the Witwatersrand, ZA; R Saini, Harisingh Gour Central U, IN: MJ Schmidt, Museu Paraense Emílio Goeldi, BR: A Shikoni, U Dodoma, TZ; A Sluyter, Louisiana State U, US; R Ssemulende, U Dar es Salaam, TZ; D Stump, U York, UK; A Styring, Goethe U Frankfurt, DE; B Sultan, RD, FR; P Szabo, Inst Botany Czech Acad Sci, CZ; E Tamanaha, Inst Mamirauá, BR; E Tello, U Barcelona, ES; E Thomas, Biodiv Internat, CO; B Vanniere, U Bourgogne Franche-Comté, FR; L Wandsnider, U Nebraska, US; M Widgren, Stockholm U, SE

\section{CONTACT}

Kathleen Morrison: kathy.morrison@sas.upenn.edu

\section{REFERENCES}

Bliege Bird R (2008) PNAS 105:14796-14801

Jouffroy-Bapicot I et al. (2007) Veg Hist Archaeobot 16: 251-258

Morrison KD et al. (2016) PAGES Mag 24: 40 